\title{
Has FDA abandoned its efforts to make fake-cigar cigarettes comply with federal tobacco control laws that apply to cigarettes but not cigars?
}

\author{
Eric N Lindblom (1) , Darren Mays, ${ }^{2}$ Kevin R J Schroth, ${ }^{3}$ Cristine Delnevo ${ }^{3}{ }^{3}$
}

\begin{abstract}
${ }^{1} O^{\prime}$ Neill Institute for National \& Global Health Law, Georgetown University Law Center, Washington, District of Columbia, USA

${ }^{2}$ Department of Oncology, Georgetown University Medical Center, Lombardi Comprehensive Cancer

Center, Washington, District of Columbia, USA

${ }^{3}$ Center for Tobacco Studies, Rutgers School of Public Health, New Brunswick, New Jersey, USA
\end{abstract}

\section{Correspondence to}

Eric N Lindblom, O’Neill Institute for National \& Global Health Law, Georgetown University Law Center, Washington, DC 20001, USA;

en127@law.georgetown.edu

Received 18 September 2019 Revised 18 December 2019 Accepted 7 January 2020 Published Online First 26 February 2020

\section{ABSTRACT}

In the USA, legal definitions of cigarettes and cigars are critical to tobacco control policy because federal, state and local laws typically tax and regulate cigarettes more strictly than cigars. In 2016, near the end of the Obama Administration, the US Food and Drug Administration (FDA) sent warning letters to four filtered 'little cigar' manufacturers stating that their so-called 'cigars' were cigarettes and, therefore, subject to more stringent public health restrictions. Documents produced in response to a Freedom of Information Act request show that without explanation or public notice FDA has abandoned its prior determination that the manufacturers' 'little cigars' were actually cigarettes and, consequently, were violating the ban on flavoured cigarettes in the Family Smoking Prevention and Tobacco Control Act (TCA). The documents also present the manufacturers' arguments against FDA's original position. However, those industry arguments are inconsistent with the research, other evidence and legal analysis indicating that filtered 'little cigars' meet the legal definition of cigarettes under the TCA and other similar federal, state and local definitions. To protect the public health, FDA must renew its efforts to ensure that these filtered 'little cigars' do not continue to evade compliance with the many important restrictions and requirements that apply to cigarettes but not cigars. Other government regulatory and taxcollection agencies with similar definitions need to follow suit.

\section{INTRODUCTION}

Legal definitions of cigarettes and cigars are critical to tobacco control policy in the USA because federal, state and local laws typically tax and regulate cigarettes more strictly than cigars and some policy restrictions, such as the 1998 Master Settlement Agreement (MSA) between the states and most cigarette companies, apply only to cigarettes. Under US federal law, for example, cigars, but not cigarettes, may be sold in packs of less than $20,{ }^{1}$ can have flavours other than menthol ${ }^{2}$ and can be delivered through the mail pursuant to internet sales. ${ }^{3}$

All the cigarette definitions in federal laws taxing and regulating tobacco products (see table 1) include: (1) any roll of tobacco wrapped in paper or in any substance not containing tobacco; (2) any roll of tobacco wrapped in any substance containing tobacco which because of its appearance, the type of tobacco used in the filler or its packaging and labelling is likely to be offered to or purchased by consumers as a cigarette. ${ }^{245}$ They also define a cigar to be any roll of tobacco wrapped in leaf tobacco or a substance containing tobacco unless it meets the definition of a cigarette. Various state and local laws and regulations, and the MSA, have parallel definitions. The cigarette definition in the Tobacco Control Act (TCA) goes even further by also including 'tobacco, in any form, that is functional in the product, which, because of its appearance, the type of tobacco used in the filler or its packaging and labelling, is likely to be offered to, or purchased by, consumers as a cigarette'. ${ }^{2}$

To try to avoid being taxed and regulated more strictly as cigarettes, manufacturers have for decades marketed rolls of tobacco only superficially different from conventional cigarettes and labelled them as 'filtered cigars' or 'little cigars'. ${ }^{6-8}$ There is ample evidence, however, that these filtered 'little cigars' still qualify as cigarettes under these definitions. Many filtered 'little cigars' are the same basic shape and size as accurately labelled cigarettes, with identical filters, and they are sold in cigarette-style packs of $20 .^{9}$ They differ in appearance only by having some tobacco in their wrapping paper and by being labelled as 'cigars'. Research also indicates that consumers view these filtered 'little cigars' as cigarettes, despite their labelling. In some surveys, respondents who self-identify as cigarette smokers list filtered 'little cigar' brands as their regular brand of cigarette, ${ }^{1011}$ and smokers of filtered 'little cigars' fail to identify themselves as cigar smokers. ${ }^{12-14}$ In other cases, researchers have structured survey questions and instructions to prompt respondents to accept manufacturers' labelling of the products as 'cigars' even when the respondents perceive them to be cigarettes. ${ }^{15-17}$ Cigarette smokers also shift to less-taxed, lower-priced filtered 'little cigars' when cigarette prices increase, further indicating that consumers consider them direct substitutes for regular cigarettes. ${ }^{18}$ Brands of filtered 'little cigars' have also appeared in response to lower tax rates on cigars than cigarettes and to evade regulations that applied to cigarettes but not cigars. ${ }^{6-8} 19$

Despite all of the evidence indicating filtered 'little cigars' meet the legal definition of cigarettes, the Food and Drug Administration (FDA), the Federal Trade Commission (FTC), the Alcohol and Tobacco Tax and Trade Bureau (TTB) and many state and local governments have continued to accept the tobacco industry's self-serving labelling of these cigarettes as 'cigars', letting them evade higher tax rates and escape the stronger public health regulations and other legal obligations that apply to cigarettes compared with cigars. However, on at least two occasions, it appeared that the FDA would no longer tolerate the mislabelling of these 
Table 1 US agencies involved in legal and regulatory control of tobacco

\begin{tabular}{|c|c|c|}
\hline Agency & Responsibilities & Cigarette definitions \\
\hline $\begin{array}{l}\text { US Food and Drug } \\
\text { Administration }\end{array}$ & $\begin{array}{l}\text { Regulates the manufacture, distribution, marketing and sale of } \\
\text { tobacco products }\end{array}$ & $\begin{array}{l}\text { The term 'cigarette' } \\
\text { A. Means a product that- - (i) is a tobacco product and (ii) meets the definition } \\
\text { of the term 'cigarette' in section 3(1) of the Federal Cigarette Labeling and } \\
\text { Advertising Act. } \\
\text { B. Includes tobacco, in any form, that is functional in the product, which, because } \\
\text { of its appearance, the type of tobacco used in the filler or its packaging and } \\
\text { labelling, is likely to be offered to, or purchased by, consumers as a cigarette or } \\
\text { as roll-your-own tobacco (21 U.S.C. } 387(3) \text { ). }\end{array}$ \\
\hline
\end{tabular}

products as filtered 'little cigars'. In September 2009, when the TCA ban on characterising flavours for cigarettes went into effect, FDA published a notice in the Federal Register stating that the ban applied to any product that met the TCA cigarette definition even if it was labelled as a 'cigar'. ${ }^{20}$

Going further, in December 2016 the FDA issued warning letters to four manufacturers for illegally selling flavoured cigarettes labelled as 'little cigars' or 'filtered cigars': Swisher International, Cheyenne International, Prime Time International and Southern Cross Tobacco. ${ }^{21}$ FDA provided the manufacturers 15 days to reply by describing their corrective actions or, if they did not believe that they were violating the TCA, to provide their reasoning and any supporting information for FDA's consideration. But FDA has not publicly released any information about any such responses or announced any FDA follow-up to the warning letters, and the products have remained on the market. Accordingly, we submitted Freedom of Information Act (FOIA) requests seeking any documents in FDA's possession relating to the warning letters. FDA released a selection of documents that included a research study conducted for the FDA on consumer perceptions of little cigars, the manufacturers' responses to the warning letters and a letter from FDA to the manufacturers indicating it considered all the compliance issues they raised resolved, provided the products complied with federal requirements relating to warning labels on cigars. $^{22}$

In this paper we analyse these FOIA documents in light of the applicable cigarette definitions, other relevant law and court rulings and related empirical evidence on filtered 'little cigar' sales, marketing, consumer perceptions and behaviour. ${ }^{23}$

\section{FDA'S CONSUMER AWARENESS AND PERCEPTION STUDY ON LITTLE CIGARS}

Prior to issuing the December 2016 warning letters, the FDA contracted with RTI International to conduct an online experiment with 3000 participants. ${ }^{22}$ Participants were randomly assigned to view an image of one of four brands of 'little cigars' appearing in four packaging styles: Carton, Open Pack, Closed Pack and Stick. While the brand and images are redacted in the report, we assume that the brands tested corresponded to those that received the warning letter and the packaging images resemble those shown in figure 1.

After viewing the image, participants were asked to classify the product shown (eg, cigarette, cigar, etc) and to indicate whether or not the product could be used as a cigarette. The open pack image and the image of the stick were more likely to be classified as cigarettes (see table 2). Indeed, on average, three out of four respondents indicated that the 'little cigars' in the open pack image were cigarettes. Additionally, brand 1, which we believe is Cheyenne, was more likely than the other brands to be classified as cigarettes-this finding was given special attention in the report. Of note, Cheyenne makes both cigarettes and 'filtered cigars with similar packaging and marketing. ${ }^{24}$ Participants also indicated at least $64 \%$ of the time, across brands and images, that the little cigar product they viewed could be used like a cigarette; this was even higher (approximately 80\%) among current tobacco users. In summary, the report concluded that 'consumers believe these little cigars are cigarettes, and could be used as cigarettes'.

\section{DO OTHER FEDERAL AGENCIES' PAST ACTIONS RELATING TO THEIR CIGARETTE DEFINITIONS CONSTRAIN FDA'S INTERPRETATION OF THE TCA'S DEFINITION?}

A primary claim by the filtered 'little cigar' manufacturers is that their products cannot be cigarettes under the TCA definition because they have been regulated historically only as cigars by the

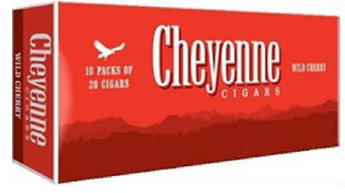

Carton

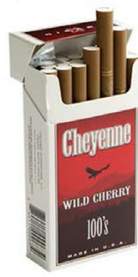

Open Pack

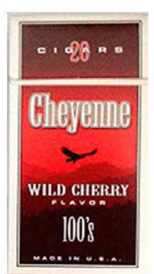

Closed Pack Stick
Figure 1 'Little cigar' images 
Table 2 Per cent classified 'little cigar' image as a cigarette: results from FDA 'little cigar' consumer study

\begin{tabular}{lllll}
\hline & Brand 1 & Brand 2 & Brand 3 & Brand 4 \\
\hline Carton & 71.6 & 47 & 26.5 & 26.8 \\
Closed pack & 75.2 & 47.5 & 33.6 & 32.6 \\
Open pack & 87 & 82.7 & 65 & 71.9 \\
Stick & 60.7 & 59.5 & 44.3 & 57.3 \\
\hline
\end{tabular}

'Little cigar' brands tested are redacted from the FDA report, but are assumed by the authors to represent the four brands that received warning letters in December 2016. It is also consensus of the authors that brand 1 is likely Cheyenne.

FDA, Food and Drug Administration.

FTC under the similar Federal Cigarette Labeling and Advertising Act (FCLAA) cigarette definition and by TTB and its predecessor, the Bureau of Alcohol, Tobacco, and Firearms (ATF), under the similar Internal Revenue Code (IRC) definition. Repeating industry arguments made in other contexts before FDA's warning letters, ${ }^{25}$ the manufacturers say their 'little cigars' cannot be reached by the federal cigarette definitions because of their past federal treatment as cigars. This core argument of the manufacturers is fatally flawed.

Court rulings clearly state that agencies are free to discard precedents or practices they no longer believe are correct, and are expected to do so in response to advances in knowledge or evidence. ${ }^{26}{ }^{27}$ Additionally, no court has ruled that the FCLAA, IRC or TCA definitions do not or cannot reach all or most filtered 'little cigars'. Consequently, the fact that certain filtered 'little cigars' have been inappropriately regulated or taxed as cigars for some time does not prevent the agencies from changing their position and reasonably exercising their discretion to re-evaluate the situation and change their practices. Agencies may substantially change their enforcement policies or their interpretations of statutory language, so long as they provide a reasoned analysis for the change. ${ }^{28} 29$

Moreover, no law or ruling requires FDA to follow FTC or TTB interpretations or practices. Although the TCA cigarette definition explicitly includes all products that meet the FCLAA definition, FDA is a separate agency operating under a separate statute with different purposes and must independently interpret and apply its definition accordingly. Despite having some parallel text, the newer, separate TCA cigarette-definition text must be separately interpreted and applied consistently with the TCA's own legislative history and its overarching goal of protecting the public health.

The TCA definition is also broader than the FCLAA definition in that it separately includes 'tobacco, in any form' (not just 'any roll of tobacco') that '.. is likely to be offered to, or purchased by, consumers as a cigarette' (21 U.S.C. 387(3)). Because of this additional provision, any legislative history, administrative actions, court rulings or other factors that might constrain the scope of the narrower FCLAA or IRC cigarette definitions, if they were legally applicable, still could not constrain the TCA cigarette definition text.

In their warning-letter response, lawyers for the manufacturer of Prime Time 'little cigars' admit the TCA definition is broader than the FCLAA definition, but claim that Congress's intent was to reach only roll-your-own tobacco and 'non-roll' forms of tobacco. However, no language in the statute or its legislative history supports this interpretation, much less requires FDA or the courts to follow it. Existing case law clearly establishes that FDA may clarify any ambiguities in the TCA, guided by the Act's public health standard, by applying the agency's unique health-directed expertise regarding tobacco product regulation. ${ }^{30}$ Indeed, FDA's determination of what kind of differences in 'appearance', 'type of tobacco' and 'packaging and labelling' are most relevant and important to distinguishing cigarettes from cigars under its cigarette definition and statutory purposes could be quite different from the FTC's or TTB's under their definitions and statutes. Likewise, FDA's determination of what constitutes 'offered to, or purchased by, consumers as a cigarette' could also be different.

Even under the narrower FCLAA cigarette definition, the most logical and reasonable interpretation would still reach filtered 'little cigars'. The manufacturers' warning-letter responses do not cite any court rulings that would interfere with such an interpretation, and there are none. Nor do the manufacturers cite any statutory language or legislative history that indicates that the FCLAA cigarette definition could not or does not reach their filtered 'little cigars'. They merely reference the statute's separate definitions for cigarettes and little cigars and state that FCLAA's legislative history indicates that its 'little cigar' definition is intended to encompass rolls of tobacco the same size and shape as conventional cigarettes. But just because some bona fide cigars could be the same size and shape of conventional cigarettes (eg, those wrapped in whole tobacco leaf with no cigarette filter) does not mean that all rolls of tobacco labelled as 'little cigars' that are the same shape and size of conventional cigarettes must not be cigarettes, either. ${ }^{31}$

The manufacturers do not cite any formal action by the FTC that explains how it perceives the dividing line between cigarettes and cigars under the FCLAA definition. But they do reference a 1973 ATF Ruling, 73-22, relating to the IRC cigarette definition. $^{32}$ That ruling, however, does not establish that the manufacturers' filtered 'little cigars' are cigars under the IRC. It only describes a preliminary test that all rolls of tobacco must pass before any further consideration as to whether they might actually be cigars under the IRC, listing necessary but not sufficient characteristics. Filtered 'little cigars' currently on the US market might satisfy some of ATF Ruling 73-22's minimum requirements for possibly qualifying as cigars under the IRC. As discussed fully below, however, some 'little cigars' violate the ruling by having a cigarette-like menthol flavour or other added flavours that were common in cigarettes but not cigars until legally restricted for cigarettes but not cigars. More importantly, as discussed below, all filtered 'little cigars' also have other characteristics that make it clear they are cigarettes, and not cigars, under the TCA.

Because of concerns that cigarettes labelled as filtered 'little cigars' were escaping the higher federal taxes on cigarettes compared with cigars, in 2006 TTB issued a proposed rule to distinguish between cigarettes and cigars under the IRC..3 No final rule was issued, possibly because TTB perceived the issue to be mooted when Congress acted to make the excise tax on little cigars parallel the tax on cigarettes. ${ }^{34}$ But the proposed rule shows that TTB had determined in 2006 that certain rolls of tobacco labelled as 'cigars', despite meeting the minimum standards in ATF Rule 73-22, were still cigarettes under the IRC definition and could be identified and taxed as such.

The 1973 ATF Ruling 73-22 also states only the agency's position regarding the interpretation and application of its statute at that time. Because it is not a final agency action, it cannot bind ATF or its successor TTB, much less restrict how FDA or the courts interpret the TCA's cigarette definition.

\section{DO FILTERED 'LITTLE CIGARS' HAVE CHARACTERISTICS THAT REQUIRE FDA TO REGULATE THEM AS CIGARS?}

Using a narrow interpretation of the key TCA language, the manufacturers argue that their 'little cigars' are not cigarettes because their 'appearance', 'type of tobacco' and 'packaging and 
labelling' are different from those of conventional cigarettes. They point out that, unlike conventional cigarettes, their products are labelled and advertised as being cigars, have non-white wrappers that contain tobacco, use different tobaccos as filler, are not always offered in packs of 20 and are offered with not only menthol flavouring, like cigarettes, but also other with flavours.

However, the TCA definition directly anticipates that some cigarettes will have tobacco in their wrapper, and some accurately labelled and regulated cigarettes currently on the market also have non-white wrappers and different types of tobacco than conventional or major-brand cigarettes. ${ }^{35}{ }^{36}$ Moreover, the only reason conventional cigarettes are not being sold in packs of less than 20, and the manufacturers' filtered 'little cigars' are, is because federal law prohibits cigarette sales in packs of less than 20 , and the 'little cigars' are evading compliance. ${ }^{37}$ Indeed, manufacturers should not be able to point to their own self-serving non-compliance with the TCA-created minimum pack size for cigarettes as a factor militating against the body of evidence that 'little cigars' actually fit within the TCA cigarette definition.

Similarly, being sold with characterising flavours other than menthol was a common cigarette characteristic before those flavours were first curtailed by a 2006 MSA settlement agreement stopping flavoured cigarette sales (other than menthol) by the Reynolds tobacco company ${ }^{38}$ and then completely prohibited for cigarettes but not cigars by the 2009 TCA ban on cigarette flavours other than menthol. ${ }^{39}$ Even when they do not have a distinguishable non-tobacco flavour, manufactured conventional cigarettes still typically include tobacco and various additives, sometimes including flavourings, sweeteners and other ingredients to make them more palatable or easier to inhaleand filtered 'little cigars' share those same characteristics. Bona fide cigars, however, originally consisted of only tobacco filler, binder leaf and whole leaf wrapper, and most products labelled as cigars (except filtered 'little cigars') typically still do. ${ }^{40}$

In particular, menthol has been an added ingredient and characterising flavour of cigarettes since the 1920s, and menthol cigarettes now constitute a large portion of the US cigarette market. ${ }^{41}$ But adding any menthol flavouring is extremely rare in conventional cigars. ${ }^{42}$ The vast majority of all tobacco products labelled as cigars that come in menthol flavour are filtered 'little cigars', which first emerged well after menthol was firmly established as a cigarette characteristic. For example, the first menthol cigarette likely appeared in 1956 (Salem menthol), ${ }^{43}$ but the first menthol 'cigars' likely first appeared in the early 1970s (Stag, Omega, Winchester), with menthol predominantly in filtered 'little cigars'. ${ }^{44}$ As ATF Ruling 73-22 indicates, having such cigarette-style menthol flavouring should further establish that filtered 'little cigars' are cigarettes. Moreover, a major reason for adding menthol into cigarettes is to make the deep inhaling associated with cigarette smoking less harsh and irritating. But industry members and others often distinguish cigars from cigarettes by noting that cigars are not inhaled or not actively inhaled while cigarettes are. ${ }^{45}{ }^{46}$ By having menthol versions and cigarette-type filters, 'little cigars' are clearly intended and expected to be inhaled deeply, just like conventional cigarettes. It also would not make sense to add menthol to a bona fide premium cigar (or add a filter) because that would directly interfere with how cigars are supposed to be smoked and 'enjoyed'. ${ }^{45}$

The characteristics the manufacturers identify as keeping their 'little cigars' outside of the TCA's cigarette definition are also entirely consistent with their being designed and labelled explicitly to try to avoid falling under applicable cigarette definitions while still serving as direct cigarette substitutes, and then taking full advantage of the weaker regulations that apply to cigars. Indeed, if these 'little cigars' were labelled as cigarettes there would be no possible justification for not regulating and taxing them as cigarettes under any of the federal definitions.

The manufacturers' responses to the warning letters do not address any of these problems with their arguments. Nor do they acknowledge, much less refute, that their 'little cigars' have key characteristics that consumers typically associate with cigarettes and do not have other key characteristics typically associated with cigars. For example, a recent study demonstrated that adults perceived having no filter or tip and being wrapped in tobacco leaf to be more like little cigars than cigarettes, and found having a filter, being able to be inhaled deeply or sold in packs of 20, and being offered in menthol or low, light and ultralight versions as being more like cigarettes than little cigars. ${ }^{47}$ The manufacturers' 'little cigars' have all these features found to be more like cigarettes, and none of these found to be more like bona fide little cigars.

\section{ARE FILTERED 'LITTLE CIGARS' LIKELY TO BE OFFERED TO, OR PURCHASED BY, CONSUMERS AS A CIGARETTE?}

The fact that filtered 'little cigars' have numerous features consumers associate with cigarettes more than little cigarsand do not have features consumers associate more with little cigars than cigarettes-is a powerful indicator that they are being 'offered to, or purchased by, consumers as a cigarette'. This is supported by the FDA's consumer awareness and perceptions study described above, which concluded 'consumers believe these little cigars are cigarettes, and could be used as cigarettes'. Other recent research also demonstrates that consumers consider filtered 'little cigars' to be substitutes for conventional cigarettes. ${ }^{47}$ These data build on the previously described evidence that, in observational studies, some individuals who self-identify as smokers identify filtered 'little cigar' brands as their regular cigarette brand, and filtered 'little cigar' smokers do not identify as cigar smokers. ${ }^{29}$ Similarly, in a recent population-based survey, $52 \%$ of those who smoked filtered 'little cigars' indicated that smoking them was like smoking a conventional cigarette. ${ }^{48}$ In their responses to FDA's warning letters, the manufacturers did not mention or rebut any of this evidence that their 'little cigars' were purchased and used by consumers as cigarettes.

The more a roll of tobacco for smoking is actively inhaled the greater the health harms and risks to the user, making that characteristic critically important for distinguishing between cigarettes and separately regulated cigars. ${ }^{49}$ Accordingly, from the purely public health perspective mandated by the TCA, whether filtered 'little cigars' are cigars or cigarettes must depend on whether they are 'likely to be offered to or purchased by consumers' for use as a cigarette, typically through active inhaling. The fact that filtered 'little cigars' have cellulose acetate filters just like cigarettes is direct evidence that they are meant to be actively inhaled and are, therefore, cigarettes. Indeed, consumers perceive having a filter and being actively inhaled as much more closely associated with cigarettes than with little cigars. ${ }^{47}$ Studies evaluating how smokers actually consume cigarettes versus 'little cigars' versus conventional cigars are scarce. But available research, including studies done by the cigarette industry, ${ }^{6}$ shows that 'little cigars' are inhaled and smoked much more like cigarettes than conventional or non-filtered cigars. ${ }^{50-53}$ 


\section{WHAT COULD AND SHOULD FDA AND OTHER GOVERNMENTAL AGENCIES DO NOW?}

For the reasons outlined here, FDA clearly could have continued its enforcement actions against the four filtered 'little cigars' manufacturers for illegally selling flavoured cigarettes and misbranding their cigarettes as filtered 'little cigars'. Indeed, FDA's own research finds that 'consumers believe these little cigars are cigarettes, and could be used as cigarettes'. ${ }^{22}$

Nothing in the FOIA documents regarding the manufacturers' responses to the warning letters supports FDA's acquiescence. Whether FDA reversed its position because of the change of Administration, other political reasons, changing enforcement priorities or simply misreading applicable law or improperly evaluating available evidence, the research and analysis that has appeared since FDA's reversal supports a change back. There are also no legal obstacles to FDA changing its interpretation of the TCA cigarette definition and actively enforcing it to reach filtered 'little cigars', so long as FDA provides a reasoned explanation for doing so. Regulating filtered 'little cigars' as cigarettes is also 'appropriate for the protection of the public health' under the TCA. While FDA could, instead, go through a formal rulemaking to regulate filtered 'little cigars' as strictly as cigarettes, including them in the TCA cigarette definition through active enforcement efforts would be a more rapid, comprehensive and accurate way to protect the public health.

Whether or not FDA renews its efforts to ensure that all cigarettes are regulated under the TCA as cigarettes, the evidence and analysis outlined here also directly supports efforts by other federal, state and local government regulatory and tax-collection agencies with similar cigarette definitions to begin treating all filtered 'little cigars' as the cigarettes they actually are.

There does not appear to be any published research regarding similar problems with cigarette versus cigar issues in other countries. But they could exist. For example, the Framework Convention on Tobacco Control (FCTC), itself, does not include a definition of cigarette (and does not mention cigars at all). ${ }^{54}$ But its illicit trade protocol defines cigarette to include only tobacco 'enclosed in cigarette paper', as well as roll-your-own tobacco for making such cigarette-paper cigarettes (and also makes no mention of cigars). ${ }^{55}$ Only the guidelines for articles 9 and 10,

\section{What this paper adds}

Documents the authors secured through the US Freedom of Information Act (FOIA) show that the US Food and Drug Administration (FDA) has stopped its prior efforts to include certain filtered 'little cigars' within the US Tobacco Control Act's (TCA's) cigarette definition, which would have required them to comply with the more extensive public health regulations that apply to cigarettes but not cigars. FDA has not publicly announced this major policy change.

- The paper critiques the FOIA-provided responses of the four manufacturers that received warning letters from FDA in December 2016 stating that their filtered 'little cigars' were actually cigarettes and were, therefore, in violation of the TCA's ban on cigarettes (but not cigars) with characterising flavours other than menthol or tobacco.

- The paper's analysis concludes that available research, including an FDA-commissioned study received from the FOIA request, show that filtered 'little cigars' fit within the TCA's cigarette definition and parallel definitions in other federal, state, and local laws. and article 11 mention cigars (once each) ${ }^{56}$; and none of the eight FCTC guidelines issued to date define either cigars or cigarettes (but the guidelines for articles 9 and 10 do reference cigarettes having 'cigarette paper'). Moreover, a recent analysis of different countries' FCTC efforts to address non-cigarette tobacco products found almost no references to national efforts directed specifically at cigars. ${ }^{57}$ At the same time, other research finds considerable tobacco industry activity to interfere with national efforts to implement the FCTC effectively. ${ }^{58}$ Fortunately, it appears that many national public health laws focus on restricting and regulating 'smoking' or 'tobacco products', thereby reaching both cigarettes and cigars. In addition, the European Union uses cigarette definitions for both public health regulation and taxation that include size and weight minimums that make it difficult for cigarettes to qualify as 'cigars' without being quite a bit larger than conventional cigarettes. ${ }^{59}$ Nevertheless, it is quite likely that some countries, following the FCTC definition, have tax or public health laws that reach conventional cigarettes but do not reach cigarettes labelled as filtered or little cigars if they are not wrapped in conventional cigarette paper. Following the analysis in this article, public health officials and non-government organizations in other countries should review their tobacco-related laws and make any required changes to ensure that they are regulating and taxing all cigarettes as cigarettes, regardless of how the industry might label them.

\section{Twitter Kevin R J Schroth @kevinschroth and Cristine Delnevo @crisdelnevo}

Contributors No substantive contributions to the paper were made by anyone other than the four listed authors. The four informally discussed the paper and what it would contain. ENL wrote the initial draft which the others reviewed, leading to numerous additions and revisions, followed by several more rounds of redrafting, comments and revisions from all four until all agreed that the final draft was accurate, complete and ready for submission. Upon receiving the revise and resubmit with comments from reviewers and the subsequent request for final changes, the same basic process repeated to produce the revised draft and then the final draft.

Funding The authors have not declared a specific grant for this research from any funding agency in the public, commercial or not-for-profit sectors.

Competing interests None declared.

Patient consent for publication Not required.

Provenance and peer review Not commissioned; externally peer reviewed. Data availability statement Data are available in a public, open access repository.

\section{ORCID iDs}

Eric N Lindblom http://orcid.org/0000-0003-0627-0987

Cristine Delnevo http://orcid.org/0000-0001-9597-4307

\section{REFERENCES}

1 Food and Drug Administration. Regulations restricting the sale and distribution of cigarettes and smokeless tobacco to protect children and adolescents. Fed. Reg 2010;75:13225-32.

2 Family smoking prevention and tobacco control act of 2009, PUB. L. No. 111-131, 21 U.S.C. Sect 2009;387.

3 Prevent all cigarette trafficking act (PACT) of 2009, PUB. L. 111-154. Stat 2009;1147.

4 Federal cigarette labeling and advertising act (FCLAA), 15 U.S.C. Sect 1985;1332.

5 Internal revenue code, 26 U.S.C. Sect 2019;5702.

6 Delnevo CD, Hrywna M. "A Whole 'Nother Smoke" or a Cigarette in Disguise: How RJ Reynolds Reframed the Image of Little Cigars. Am J Public Health 2007;97:1368-75.

7 Delnevo CD, Hrywna M, Giovenco DP, et al. Close, but no cigar: certain cigars are pseudo-cigarettes designed to evade regulation. Tob Control 2017;26:349-54.

8 Delnevo CD, Hrywna M. Clove cigar sales following the US flavoured cigarette ban. Tob Control 2015;24:e246-50.

9 Gammon DG, Rogers T, Coats EM, et al. Little filtered cigars: US sales, flavours, package sizes and prices. Tob Control 2019;28:346-9.

10 Casseus M, Garmon J, Hrywna M, et al. Cigarette smokers' classification of tobacco products. Tob Control 2016;25:628-30.

11 Rait MA, Prochaska JJ, Rubinstein ML. Reporting of cigar use among adolescent tobacco smokers. Addict Behav 2016;53:206-9. 
12 Terchek JJ, Larkin EMG, Male ML, et al. Measuring cigar use in adolescents: inclusion of a brand-specific item. Nicotine Tob Res 2009;11:842-6.

13 Trapl ES, Terchek JJ, Danosky L, et al. Complexity of measuring "cigar use" in adolescents: results from a split sample experiment. Nicotine Tob Res 2011;13:291-5.

14 Nasim A, Blank MD, Berry BM, et al. Cigar use Misreporting among youth: data from the 2009 youth tobacco survey, Virginia. Prev Chronic Dis 2012;9:110084.

15 Dickinson DM, Johnson SE, Coleman BN, et al. The language of cigar use: focus group findings on cigar product terminology. NICTOB 2016;18:850-6.

16 Nyman AL, Sterling KL, Weaver SR, et al. Little Cigars and Cigarillos: users, perceptions, and reasons for use. tobacco reg sci 2016;2:239-51.

17 Corey CG, Dube SR, Ambrose BK, et al. Cigar smoking among U.S. students. Am J Prev Med 2014;47:S28-35.

18 Gammon DG, Loomis BR, Dench DL, et al. Effect of price changes in little cigars and cigarettes on little cigar sales: USA, Q4 2011-Q4 2013. Tob Control 2016;25:538-44.

19 NBC News. Importer tries to get around clove cigarette ban, 2009. Available: http:// www.nbcnews.com/id/32723154/ns/business-retail/t/importer-tries-get-around-clovecigarette-ban/\#.XFBvWGI7nRY [Accessed 28 Dec 2019].

20 Federal Register. Enforcement of general tobacco standard special rule for cigarettes, 2009. Available: https://www.federalregister.gov/documents/2009/09/25/E9-23144/ enforcement-of-general-tobacco-standard-special-rule-for-cigarettes [Accessed 28 Dec 2019].

21 Food and Drug Administration. Fda letters to each of the four manufacturers, 2016. Available: http://oneill.law.georgetown.edu/foia-documents [Accessed 28 Dec 2019].

22 Food and Drug Administration. Fda letters to each of the four manufacturers, 2018 Available: http://oneill.law.georgetown.edu/foia-documents [Accessed 28 Dec 2019].

23 The manufacturers responses included the following documents: Chief Executive Officer, Cheyenne International, LLC, Cheyenne International, Re: LLC Warning Letter Response, December 30, 2016; Will Woodlee, Counsel, Prime Time International Distributing, Inc, Re:Warning Letter, dated December 9, 2016, Issue to Prime Time International Distributing, Inc, January 12, 2017; [Redacted Signatory], Southern Cross Tobacco Company, Inc, Re: RW1600607 12/9/2016 Warning Letter Issued to Southern Cross Tobacco Company, Inc. Pertaining to Criss-Cross Cherry 100's Filtered Cigars, January 13, 2017; Anna Laakmann, Counsel for Swisher International, Inc, Re: Response to Warning Letter Issued to Swisher International, Inc. Available: http:// oneill.law.georgetown.edu/foia-documents [Accessed 28 Dec 2019].

24 Campaign for tobacco free kids. Cheyenne cigarettes and cigars look alike (slide show). Available: https://www.tobaccofreekids.org/assets/content/what_we_do/ industry_watch/kittylitter/slide_2.html [Accessed 28 Dec 2019].

25 Alcohol and tobacco Tax and trade bureau, Treasury, notice of proposed rulemaking, Tax classification of Cigars and cigarettes (2006R-276P) 2006.

26 Williams gas processing V. FERC 475 F.3d 319, 326 (dC CIR.) 2006

27 Appeals USC of, Circuit D of C. 567 F2d 1016 American Public Gas Association v. Federal Power Commission. 1977;F2d:1016. [Citing Mobil Oil Corp. v. FPC, 417 U.S. 283, 320 (1974)] 1974:283:320.

28 Motor Veh. Mfrs. Ass'n v. State Farm Ins., 463 U.S. 291983.

29 Fcc V. Fox television stations, Inc., 556 U.S. 5022009

30 Chevron U.S.A., Inc. V. NRDC, 467 U.S. 8371984

31 Rate of tax - Content Details - USCODE-2011-title26-subtitleE-chap52-subchapAsec5701, 26 U.S.C. Sect 2012;5701.

32 Atf ruling, 73-22 1973.

33 Federal Register. Tax Classification of Cigars and Cigarettes. 71(206): 62506-23 2006

34 Children's Health Insurance Program Reauthorization Act of 2009, Pub. L. 111-3, 48 Stat. 9982009.

35 Nat Sherman Fantasia brand cigarettes (multiple different colored wrappers) and MCD Luxury brand cigarettes (brown) [Internet]. Pro Smokes. Available: http://www. pro-smokes.com/buy-online-cigarettes/nat-sherman.aspx [Accessed 28 Dec 2019].
36 Sobranie Black Russian Brand (black) and Cocktail Brand (multiple colors) [Internet]. Discount cigarettes. Available: http://www.discountcigarettesmall.com/sobraniecigarettes [Accessed 28 Dec 2019]

3721 code of federal regulations, 1140.162018.

38 Dachille K. Tobacco control legal Consortium. Pick Your Poison: Responses to the Marketing and Sale of Flavored Tobacco Products 2009.

39 standards Tproduct. 387g(a)(1)(A) U.S.C. Sect 2009;907

40 Cigars international. cigar 101, cigar basics, 2019. Available: https://www. cigarsinternational.com/cigar-101/cigar-basics/1818003 [Accessed 28 Dec 2019].

41 McNichol T. Mint that kills: the curious life of menthol cigarettes. The Atlantic, 2011 Available: https://www.theatlantic.com/health/archive/2011/03/mint-that-kills-thecurious-life-of-menthol-cigarettes/73016 [Accessed 28 Dec 2019].

42 Kuiper NM, Gammon D, Loomis B, et al. Trends in sales of flavored and menthol tobacco products in the United States during 2011-2015. Nicotine Tob Res 2018:20:698-706

43 Gardiner P. The African Americanization of menthol cigarette use in the United States. Nicotine \& Tobacco Res. 2004:6:55-65

44 Kostygina G, Glantz SA, Ling PM. Tobacco industry use of flavours to recruit new users of little cigars and cigarillos. Tob Control 2016;25:66-74.

45 How to Smoke a Cigar Like You Actually Know What You're Doing | The Manual. The Manual, 2019. Available: https://www.themanual.com/culture/how-to-smoke-a-cigarproperly [Accessed 28 Dec 2019].

46 Herling S, Kozlowski LT. The importance of direct questions about inhalation and daily intake in the evaluation of pipe and cigar smokers. Prev Med 1988;17:73-8.

47 Lindblom EN, Johnson AC, Gray T, et al. How and Why Consumers View "Little Cigars" as Legally-defined Cigarettes. tob regul sci 2019;5:124-34.

48 Corey CG, Holder-Hayes E, Nguyen AB, et al. Us adult cigar smoking patterns, purchasing behaviors, and reasons for use according to cigar type: findings from the population assessment of tobacco and health (path) study, 2013-2014. Nicotine Tob Res 2018;20:1457-66.

49 Chang CM, Corey CG, Rostron BL, et al. Systematic review of cigar smoking and all cause and smoking related mortality. BMC Public Health 2015;15:390.

50 Pickworth WB, Rosenberry ZR, Koszowski B. Toxicant exposure from smoking a little cigar: further support for product regulation. Tob Control 2017;26:269-76.

51 Pickworth WB, Rosenberry ZR, O'Grady KE, et al. Dual use of cigarettes, little Cigars, Cigarillos, and large Cigars: smoking topography and toxicant exposure. tob regul sci 2017;3:72-83

52 Koszowski B, Rosenberry ZR, Yi D, et al. Smoking behavior and smoke constituents from Cigarillos and little Cigars. Tob Regul Sci 2017:3:31-40.

53 Rosenberry ZR, Pickworth WB, Koszowski B. Large Cigars: smoking topography and toxicant exposure. Nicotine Tob Res 2018:20:183-91.

54 World Health Organization. Framework convention on tobacco control (FCTC). Available: https://www.who.int/fctc/

55 World Health Organization. Framework convention on tobacco control: protocol to eliminate illicit trade in tobacco products. Available: https://www.who.int/fctc/ protocol/en/

56 World Health Organization. World Health organization. Partial guidelines for implementation of articles 9 and 10 (2012); FCTC, guidelines for implementation of article, 2011. Available: https://www.who.int/fctc/treaty_instruments/adopted/en

57 Zaatari GS, Bazzi A. Impact of the who FCTC on non-cigarette tobacco products. Tob Control 2019;28:s104-12.

58 Bialous SA. Impact of implementation of the who FCTC on the tobacco industry's behaviour. Tob Control 2019:28:594-6.

59 European Parliament and of the Council. European directive 2014/40/EU of the European Parliament and of the Council, 2014. Available: https://ec.europa.eu/health/ sites/health/files/tobacco/docs/dir_201440_en.pdf 